\title{
Rates of decline and recovery of coral cover on reefs impacted by, recovering from and unaffected by crown-of-thorns starfish Acanthaster planci: a regional perspective of the Great Barrier Reef
}

\author{
Martin J. Lourey*, Daniel A. J. Ryan, Ian R. Miller \\ Australian Institute of Marine Science, PMB No. 3, Townsville Mail Centre 4810, Queensland, Australia
}

\begin{abstract}
Manta tow surveys of the perimeters of reefs throughout the Great Barrier Reef (GBR) assessed broad-scale changes in hard coral cover on reefs impacted by, recovering from and unaffected by Acanthaster planci outbreaks. Mean coral cover was 16 to $40 \%$ on reefs with no history of $A$. planci outbreaks, depending on location on the GBR. Coral cover increased at approximately $2 \% \mathrm{yr}^{-1}$ on southern reefs, while there was no significant increase on such reefs in other regions. Hard coral cover on reefs with $A$. planci outbreaks declined at a mean annual rate of $6 \%$ to an average level of $9 \%$. Coral cover on southern reefs that were recovering from sustained $A$. planci outbreaks increased at about $4 \% \mathrm{yr}^{-1}$ while such reefs showed an annual increase of $0.8 \%$ in the remaining regions. A total of $78 \%$ of recovering reefs showed a positive growth rate, assuming linear growth, the time for coral cover to increase by $30 \%$, was estimated at between $5 \mathrm{yr}$ and well over $1000 \mathrm{yr}$. In addition to providing regional estimates of the decline and recovery of reefs due to A. planci outbreaks, this study highlights the variability in rate of recovery between reefs and raises the possibility that not all reefs will recover from sustained outbreaks.
\end{abstract}

KEY WORDS: Coral · Recovery - Mortality · Manta tow Great Barrier Reef · Crown-of-thorns starfish $\cdot$ Acanthaster planci

\section{INTRODUCTION}

Outbreaks of crown-of-thorns starfish Acanthaster planci (Linnaeus) have been implicated in widespread coral mortality throughout the Indo-Pacific (Birkeland \& Lucas 1990). Certainly, large areas of the Great Barrier Reef (GBR) have been damaged by starfish outbreaks (Moran et al. 1992). Disturbance is common on coral reefs and there is a corresponding capacity for recovery and recolonisation (Hughes et al. 1992). Estimates of the time required for hard coral cover to return to pre-outbreak levels on the GBR range from 10 yr (Moran et al. 1985) to over 50 yr (Done 1988).

\footnotetext{
- Present address: Institute of Antarctic and Southern Ocean Studies, University of Tasmania, PO Box 252-77. Hobart, 7001. Tasmania, Australia. E-mail: mlourey@utas.edu.au
}

Previous studies on the impact of Acanthaster planci outbreaks on the GBR have been limited in scope. They only considered small spatial scales, on few reefs $(<3$ reefs) (Done 1985, 1987, Moran et al. 1985, Done et al. 1988, Fisk et al. 1988). They used survey techniques, such as quadrats and line transects, that are limited to small areas of reef Endean \& Stablum 1973, Pearson 1974, 1981, Done 1987, 1988, Done et al. 1988, Endean et al. 1988) and may not be representative when extrapolated to larger areas (Moran 1986). They covered short temporal series ( 1 to 3 surveys) initiated in response to A. planci outbreaks (Endean \& Stablum 1973, Pearson 1974, Moran et al. 1985, Endean et al. 1988).

In principle, an outbreak of Acanthaster planci occurs when a population on a reef reaches such levels that corals are being consumed faster than they can grow. A quantitative definition of an outbreak is hard to provide due to differences in survey technique, cryptic starfish 
behaviour and variability in the distribution and intensity of outbreaks (Moran 1986). A variety of definitions for an outbreak are summarized in Moran \& De'ath (1992a). Defining a recovering reef is also difficult; some consider that a reef has recovered if coral cover reaches pre-outbreak levels (Pearson 1981, Connell 1997); while others would argue that colony size-structure, reproductive activity, growth rates, species composition and diversity must all return to the pre-outbreak state for true recovery (Connell 1997). In either case, definition of an outbreak or a recovery has been closely tied to the method used to quantify the number of $A$. planci on a reef.

Manta tows give reef-wide estimates of benthic cover (Done et al. 1981, Moran \& De'ath 1992b, Miller \& De'ath 1996) and have been widely used to estimate Acanthaster planci numbers. While the technique underestimates A. planci numbers (Fernandes 1990, Fernandes et al. 1990, 1992), estimates from manta tows and scuba search compare favourably and the former can be used to predict the latter (De'ath 1992, Moran \& De'ath 1992b). Precision of coral cover estimates can be maintained by regular training (Miller \& De'ath 1996, Miller \& Müller 1997).

Staff of the Australian Institute of Marine Science have used manta tows since 1985 to estimate reef-wide hard coral cover levels and the average numbers of Acanthaster planci on a large number of reefs distributed throughout the GBR. Here we use data collected between 1985 and 1997 to provide a regional perspective of the A. planci phenomenon on the GBR.

This paper aims to address the following questions: (1) Does coral cover vary with position of reefs on the GBR? (2) What is the historical distribution of Acan- thaster planci outbreaks on the GBR? (3) What is the relationship between $A$. planci outbreaks and coral cover? (4) How does coral growth on reefs affected by $A$. planci outbreaks compare with growth on reefs with no history of A. planci? (5) How quickly do reefs recover after $A$. planci outbreaks?

\section{MATERIALS AND METHODS}

Field methods. Manta tows (Bass \& Miller 1995) have been used to estimate Acanthaster planci numbers and hard coral cover on 522 individual reefs distributed throughout the GBR. These reefs were visited annually where possible, though many reefs were only visited occasionally. Reefs were classified into 4 regions (Fig. 1) (far northern, northern, central and southern) and 2 shelf positions (GBR Lagoon and exposed to the Coral Sea).

Manta towing requires a team of 2 investigators (a boat driver and an observer) in a small boat. The driver uses prominent reef features to follow a predefined path around the perimeter of the reef while towing the observer on a manta board at a steady speed (approximately 1 to 1.5 knots). The driver stops the boat at 2 min intervals and the observer records the number of Acanthaster planci observed and an estimate of the hard coral cover in a $10 \mathrm{~m}$ wide strip extending down from the reef crest (see Table 1 for the categories used). Training ensures standardised observations and reduced observer error (Miller \& De'ath 1996). Regular comparisons between observers maintain consistency (Miller \& Müller 1997).
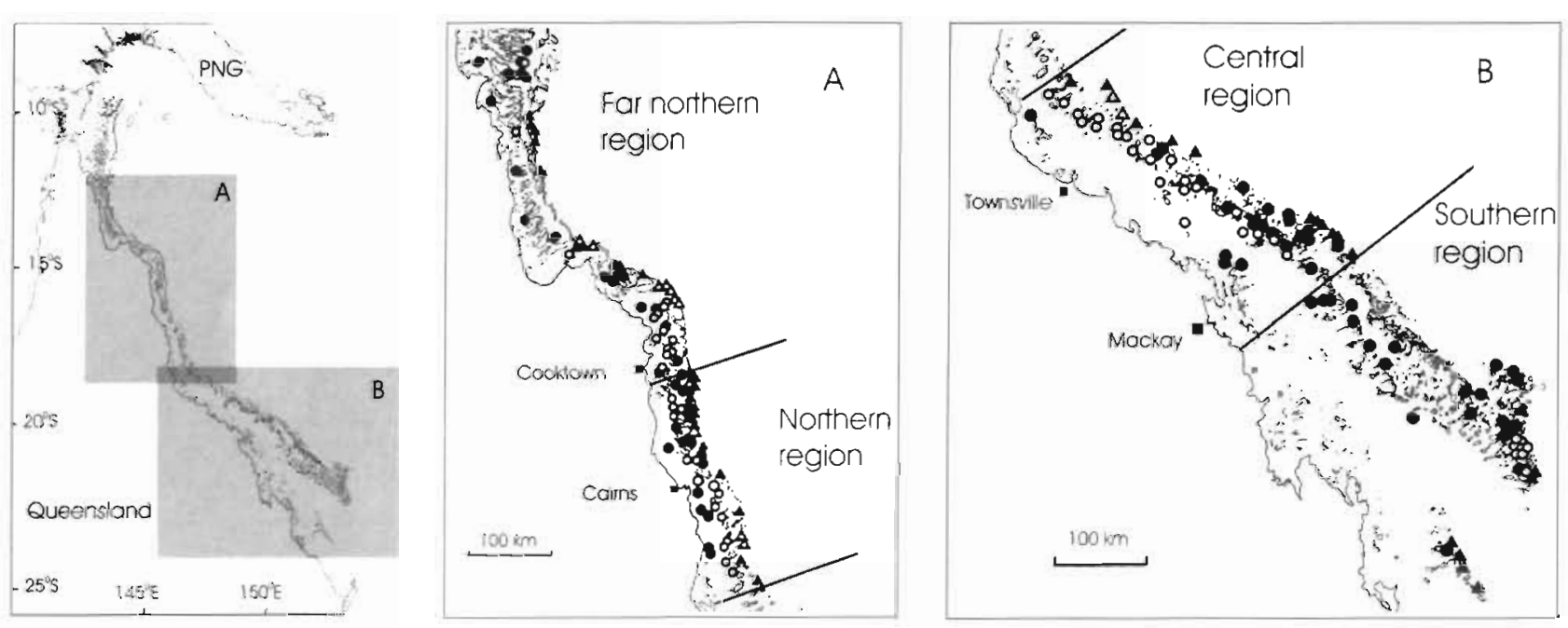

Fig. 1. Map of the Great Barrier Reef highlighting the spatial distribution and status of reefs used in the analysis. ( $\bullet$ ) Inner shelf reefs with no history of Acanthaster planci outbreaks, $(0)$ inner shelf reefs with a history of $A$. planci outbreaks, ( $\mathbf{\Delta})$ outer shelf reefs with no history of $A$. planci outbreaks and $(\Delta)$ outer shelf reefs with a history of $A$. planci outbreaks 
We considered 306 reefs (Fig. 1) with no history of Acanthaster planci outbreaks and 216 reefs which had outbreak populations of $A$. planci at some point since 1985 (these reefs are defined as having had an outbreak history). Records for reefs which had supported outbreaks were further subdivided into periods of outbreak (a density of at least $0.22 \mathrm{~A}$. planci per $2 \mathrm{~min}$ tow) and recovery (a density of less than $0.22 \mathrm{~A}$. planci per 2 min tow) as argued by Moran \& De'ath (1992a). Reefs that experienced cyclone damage were excluded from the analysis.

Statistical methods. Regional differences in reefwide hard coral cover for 306 reefs with no Acanthaster planci history were examined using a 2-factor analysis of variance (ANOVA) on the logit transformed (McCullagh \& Nelder 1989) average hard coral cover estimates for individual reefs. The factors were region (far northern, northern, central and southern; Fig. 1) and shelf position (GBR Lagoon and exposed to the Coral Sea). Contrasts were used to compare reef means.

The regional distribution of reefs that had a history of Acanthaster planci outbreaks was examined by classifying reefs as either having an observed outbreak during the course of the survey or having no observed outbreak during the course of the survey. This classification creates a binomial response, history of outbreak or not, and logistic regression was used to examine the relationship between this response and regional factors.

The average coral cover in the first year after a sustained outbreak was obtained from 40 reefs. A sustained outbreak occurred when outbreak populations were observed in at least 3 consecutive surveys of a reef (not necessarily annual).

The rate of change in hard coral cover (expressed as $\%$ of total cover per year) was estimated for 138 reefs with no history of Acanthaster planci outbreaks, using simple linear regression. For reefs with a history of $A$. planci outbreaks, simple linear regression was used to estimate the rate of change in hard coral cover for periods of outbreaks and of recovery. Only periods where the reef's status remained the same for at least 3 con-

Table 1. Categories used to estimate hard coral cover using the manta tow technique

\begin{tabular}{|lcc|}
\hline $\begin{array}{l}\text { Recorded cover } \\
\text { category }\end{array}$ & $\begin{array}{c}\text { Range of cover } \\
\text { included in each } \\
\text { category }(\%)\end{array}$ & $\begin{array}{c}\text { Midpoint of range } \\
\text { for each } \\
\text { category }(\%)\end{array}$ \\
\hline 0 & 0 & 0 \\
1 & $<1-10$ & 5 \\
2 & $11-30$ & 20 \\
3 & $31-50$ & 40 \\
4 & $51-75$ & 62.5 \\
5 & $76-100$ & 87.5 \\
\hline
\end{tabular}

secutive surveys were included. This resulted in 77 estimates for periods of recovery and 22 estimates for periods of sustained outbreak from 81 reefs (some reefs experienced both outbreaks and recovery in the duration of the study). The rates of change in coral cover on reefs experiencing a sustained outbreak were examined for regional differences (e.g. position on the continental shelf and region) using a 2 -way mixed model. The rates of change in coral cover on reefs that were recovering from an $A$. planci outbreak were compared with those for reefs that had not experienced an outbreak using a 3-way mixed linear model (effects of interest: reef status, regional differences, shelf position and interactions between these factors). Regional differences in the percentage of reefs with increasing coral cover were examined using logistic regression. We estimated the median length of time required for an arbitrary $30 \%$ increase in absolute hard coral cover (i.e. from $x \%$ to $x+30 \%$ ) on reefs where coral cover was increasing.

\section{RESULTS}

\section{Hard coral cover on GBR reefs with no Acanthaster planci outbreak history}

The difference in hard coral cover between innershelf reefs and outer-shelf reefs appeared to be largest in the northern region, with no apparent differences in the remaining regions (Fig. 2). Although the interaction between region and shelf position appeared to be large (Fig. 2), it was not significant at the $5 \%$ level ( $\mathrm{p}=$ 0.079 ). It was decided that it would be of interest to test the difference between the inner-shelf reef means for the 4 sectors and to test the difference between the outer-shelf reef means for the 4 sectors. As these comparisons were suggested by the data, the p-values used were adjusted using a correction for contrasts described by Scheffe (Snedecor \& Cochran 1980). There were significant differences in hard coral cover among the inner-shelf reefs in the 3 northern sectors. Hard coral cover on inner-shelf reefs of the northern region $(16 \%)$ was not significantly lower than innershelf reefs in the central region $(23 \%, p=0.303)$, but was significantly lower than inner-shelf reefs in the far northern region $(28 \%, p=0.003)$. Southern inner-shelf reefs were significantly higher than the average of the remaining 3 sectors $(38 \%, \mathrm{p}<0.001)$. Comparisons of the outer-shelf means suggested that hard coral cover on outer-shelf reefs in the far northern, northern and central regions were not significantly different (all $\mathrm{p}>$ 0.50 ), but the southern outer-shelf reefs were significantly higher than the average of the remaining sectors $(\mathrm{p}=0.009)$ 


\section{Historical distribution of Acanthaster planci outbreaks}

The percentage of reefs with a history of Acanthaster planci outbreaks ranged from $6 \%$ of outer-shelf reefs in the southern region to $50 \%$ of innershelf reefs in the northern region (Fig. 3). There were significant trends across the continental shelf $(p=0.007)$ and among regions $(\mathrm{p}<0.001)$, though there was no evidence of a significant interaction between these factors $(\mathrm{p}=$ 0.908). Inner-shelf reefs were more likely to have a history of $A$. planci outbreaks than outer-shelf reefs $(\mathrm{p}=$ 0.007 ), while reefs in the southern region were less likely to have a history of $A$. planci outbreaks than reefs in the remaining regions $(\mathrm{p}<0.001)$. There was no evidence of significant differences in the proportion of reefs that had $A$. planci outbreaks among the remaining regions $(p=0.329)$.

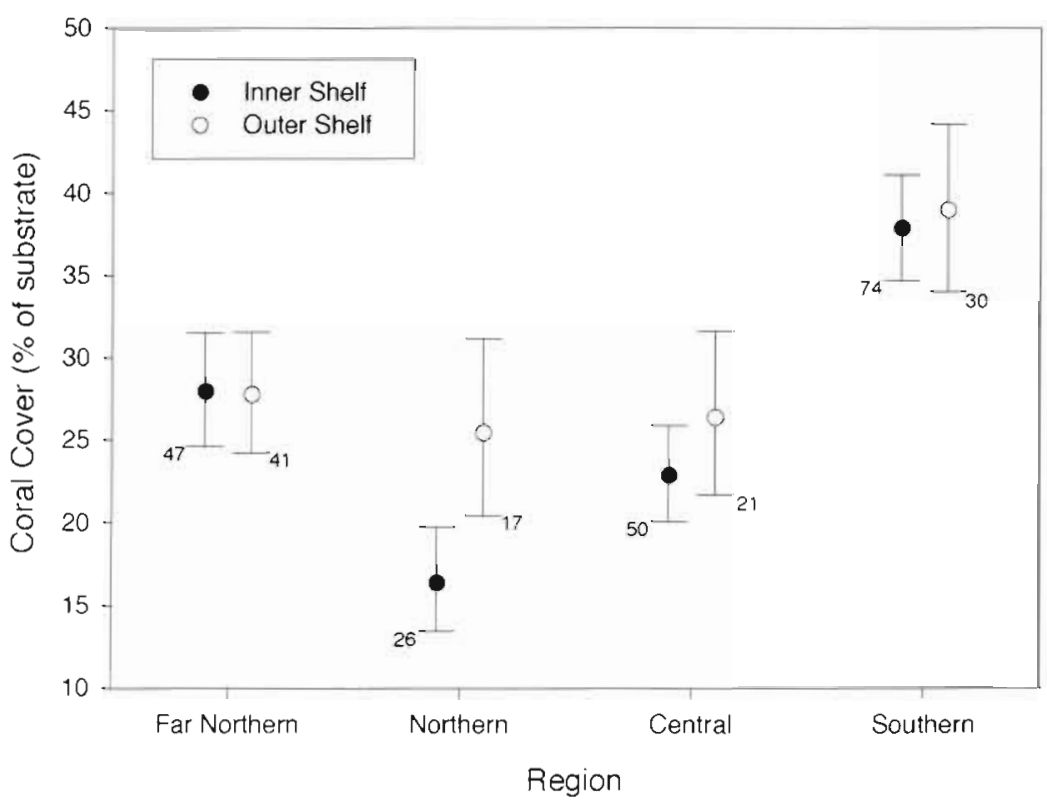

Fig. 2. Mean hard coral cover for reefs with no history of Acanthaster planci outbreaks in different regions of the Great Barrier Reef. Error bars are $95 \%$ confidence interval for the mean. The numbers indicate the number of reefs in each region shelf position

\section{Effect of Acanthaster planci on hard coral cover}

Hard coral cover was reduced by an average of $6 \%$ (absolute) per year ( $95 \%$ confidence interval: 2 to $9 \%$ )

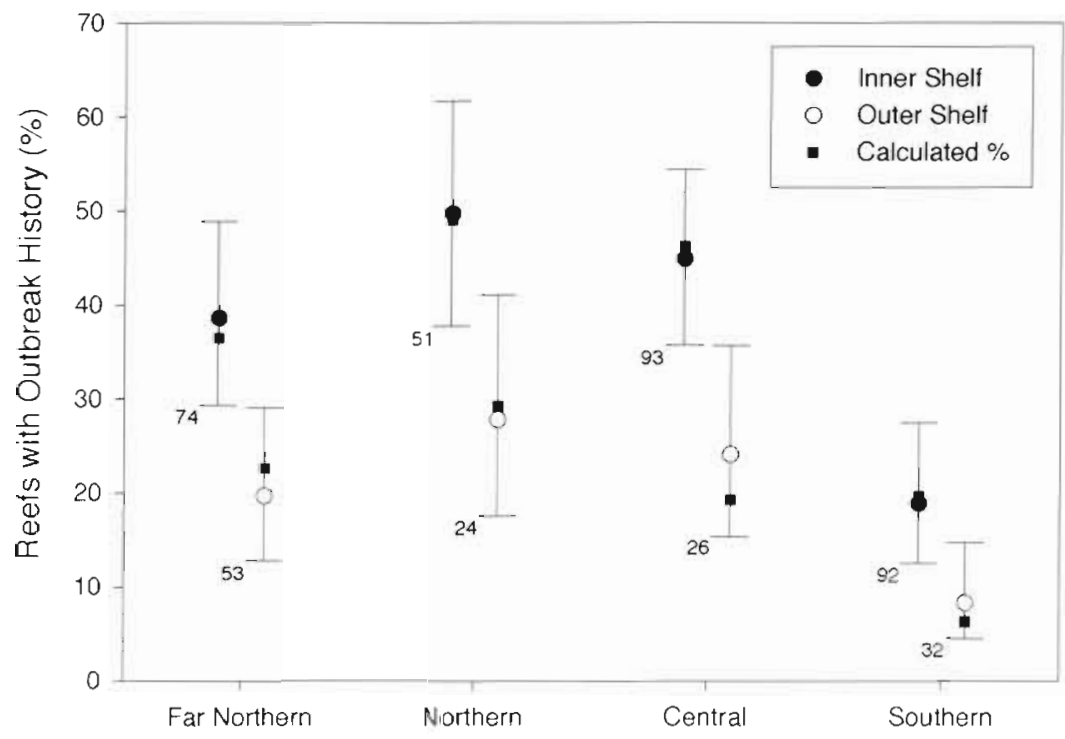

Fig. 3. Estimated proportion of reefs classified by region and shelf position that

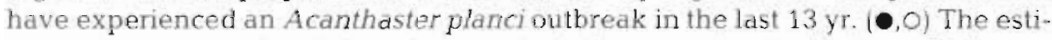
mated proportion of reefs based upon a logistic regression, including a $95 \%$ confidence interval for this value, and. (a) the observed percentage of reefs that have experienced an outbreak in the last $13 \mathrm{yr}$ are shown. The numbers indicate the number of reets in each region shelf position on reefs experiencing sustained Acanthaster planci outbreaks. The rate of decrease did not differ among the regions $(p=0.256)$. In the first year after a sustained outbreak, hard coral cover on reefs ranged from 2 to $28 \%$ and averaged $9 \%(95 \%$ confidence interval: 7 to $11 \%$ ). In contrast, average hard coral cover on reefs with no outbreak history ranged from 16 to $40 \%$ (Fig. 2).

\section{Growth and recovery of hard corals on the GBR}

Hard coral cover increased faster on average on reefs recovering from sustained outbreaks than on reefs with no history of Acanthaster planci outbreaks ( $p=0.029)$. Rates of change in coral cover also differed among regions ( $p=0.012)$. No interactions between the status and regional factors were significant at the $5 \%$ level (Table 2). The largest differences in rates of change of hard coral cover among the regions occurred between the southern region and the remaining regions (Fig. 4, Table 3). The estimated increase in hard coral cover for 
Table 2. Tests of the fixed effects for the 3-way mixed model examining differences in the rate of change of hard coral cover due to the fixed effects of latitude (Region), cross-shelf position (Shelf) and Acanthaster planci history of the reef (Status)

\begin{tabular}{|lccc|}
\hline Effect & $\begin{array}{c}\text { Numerator } \\
\mathrm{df}\end{array}$ & $F$-value & $\mathrm{p}$-value \\
\hline Region & 3 & 3.77 & 0.012 \\
Status & 1 & 4.81 & 0.029 \\
Shelf & 1 & 0.89 & 0.347 \\
Region $\times$ Status & 3 & 2.12 & 0.099 \\
Region $\times$ Shelf & 3 & 1.22 & 0.305 \\
Shelf $\times$ Status & 1 & 1.09 & 0.299 \\
Region $\times$ Shelf $\times$ Status & 2 & 0.73 & 0.484 \\
\hline
\end{tabular}

recovering reefs averaged over the far northern, northern, and central regions was $0.8 \% \mathrm{yr}^{-1}$. This contrasted with the increase of $0.2 \% \mathrm{yr}^{-1}$ for reefs in these regions with no $A$. planci outbreak history (Table 4). Rates of increase for hard coral cover on southern reefs averaged $4 \% \mathrm{yr}^{-1}$ on recovering reefs and $2 \% \mathrm{yr}^{-1}$ on reefs with no history of outbreaks (Table 4).

\section{Time to recovery after a starfish outbreak}

The percentage of recovering reefs where coral cover was increasing ranged from $88 \%$ in the far northern region to $70 \%$ in the northern region (Table 5), though regional differences in the percentage of reefs showing positive rates of change were not significant $(\mathrm{p}=0.956)$. Coral cover was increasing on $78 \%$ of all recovering reefs. Assuming linear growth rates on these reefs, the time required for the hard coral cover to increase by $30 \%$ of total cover after a sustained Acanthaster planci outbreak ranged from 5 to $>1000$ yr for reefs in the 3 northern regions and from 2 to $\sim 300$ yr for reefs in the southern region (Table 6).

\section{DISCUSSION}

\section{Hard coral cover on GBR reefs with no Acanthaster planci outbreak history}

Hard coral cover on reefs with no history of Acanthaster planci outbreaks was lowest on inner-shelf reefs in the northern and central regions. These regions are adjacent to watersheds
Table 3. Estimated differences in rates of hard coral growth among the 4 regions. The standard error is of the estimated difference, and the p-value is associated with the test that the estimated difference is significantly different from zero

\begin{tabular}{|lccc|}
\hline $\begin{array}{l}\text { Regions } \\
\text { compared }\end{array}$ & $\begin{array}{l}\text { Estimated } \\
\text { difference }\end{array}$ & SE & p-value \\
\hline FN and NO & 0.69 & 0.33 & 0.038 \\
FN and CN & 0.72 & 0.53 & 0.171 \\
FN and SO & -1.71 & 0.86 & 0.050 \\
NO and CN & 0.03 & 0.51 & 0.952 \\
NO and SO & -2.40 & 0.86 & 0.006 \\
CN and SO & -2.43 & 0.95 & 0.011 \\
\hline
\end{tabular}

that have been extensively modified by human activity (Moss et al. 1992). This is the pattern one might expect if anthropogenic impacts, such as nutrient-enriched run off, hinder growth and recruitment of corals (Hatcher et al. 1989, Bell 1992). Interestingly, the hard coral cover on outer shelf reefs of the far northern, northern and central regions was quite similar (Fig. 2), suggesting that if the anthropogenic impacts are associated with the reduced cover on the inner-shelf reefs, these impacts may not extend to the outer shelf. However, this is an observational study that can reveal little about processes. Other factors such as larval dispersal patterns, recruitment patterns and community composition may be the driving forces behind these observations.

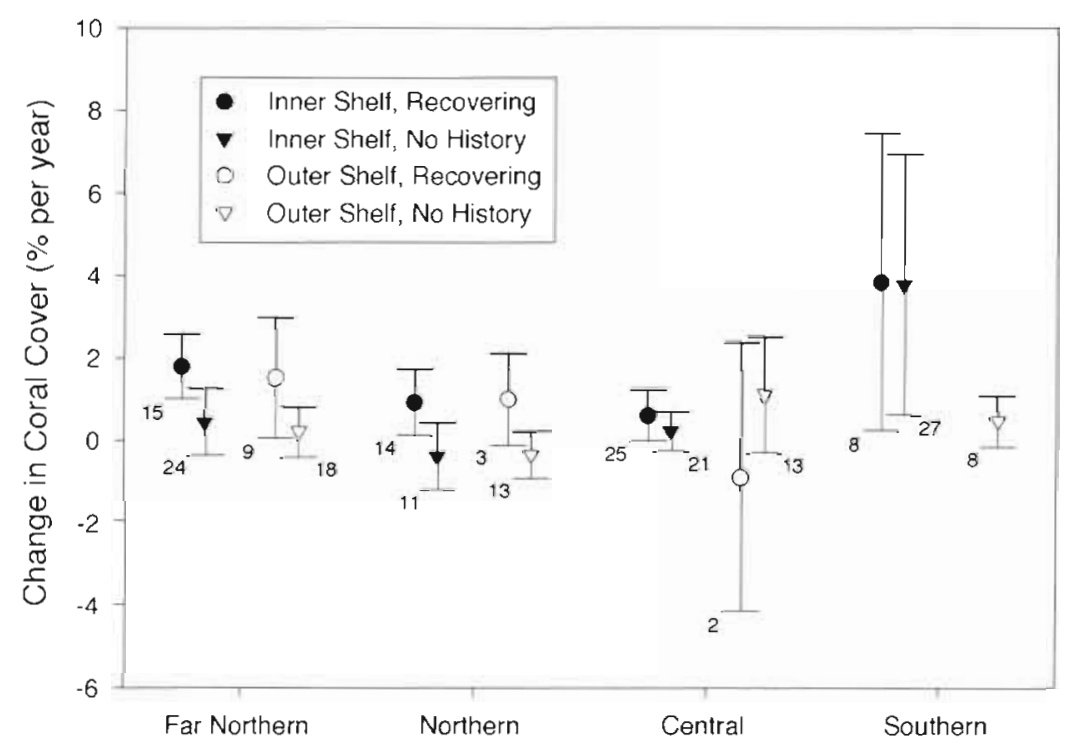

Fig. 4. Estimated rates of change in hard coral cover from reefs with outbreaking populations of Acanthaster planci, reefs recovering after an outbreak and reefs with no outbreak history. Includes a $95 \%$ confidence interval for the rate of change. The numbers indicate the number of observations in each category 
Table 4. Estimated increase in hard coral cover for reefs with no history of Acanthaster planci outbreaks (No History) and reefs recovering from sustained outbreaks of $A$. planci (Recovering)

\begin{tabular}{llccc|}
\hline Region & \multicolumn{1}{c}{ Status } & Estimate & SE & p-value \\
\hline Southern & No History & 2.14 & 0.83 & 0.011 \\
Others & No History & 0.22 & 0.18 & 0.205 \\
Southern & Recovering & 3.87 & 1.85 & 0.038 \\
Others & Recovering & 0.84 & 0.34 & 0.013 \\
\hline
\end{tabular}

\section{Acanthaster planci on GBR reefs}

In each region the percentage of reefs with a history of Acanthaster planci outbreaks was consistently higher for inner-shelf reefs, confirming the observations of Moran (1986). The proportion of reefs with an A. planci history was higher in the far northern, northern and central regions of the GBR than in the southern region. It is interesting to note that the region with the highest mean hard coral cover also had the lowest proportion of reefs that had experienced an A. planci outbreak and vice versa. This result cannot be attributed directly to $A$. planci since the hard coral cover estimates were based on reefs with no history of outbreaks. Thus factors that affect the distribution of the hard coral cover may have an opposite effect on the distribution of A planci.

There was a dramatic reduction in hard coral cover on individual reefs due to sustained Acanthaster planci outbreaks: the cover was reduced on average by $6 \% \mathrm{yr}^{-1}$. The mean coral cover on reefs immediately after an outbreak $(9 \%)$ was low compared to reefs with no outbreak history. However, both the cover remaining after an $A$. planci outbreak and the rate of coral mortality varied greatiy from reef to reef. This is not surprising considering the differences in the density and distribution of outbreaking populations within and between reefs (Moran 1986).

\section{Coral growth and recovery on GBR reefs}

Unlike other parts of the world (such as the Western Atlantic) that have not shown high levels of recovery after disturbance (Connell 1997), change in coral cover on recovering reefs was positive and significantly different from zero. This suggests that, in general, conditions on the GBR are sufficient for coral recruitment and growth on reefs severely impacted by Acanthaster planci. The differences in recovery rates are most likely due to the type of disturbance (acute vs chronic), distribution of reefs (the area likely to be affected by disturbance) and/or differences in recruitment and mortality rates (Connell 1997, Connell et al. 1997). Reefs with no outbreak history showed no significant rate of change in coral cover. Factors affecting recruitment or post-settlement competition may result in slower growth rates than on reefs where easily colonisable space is available. From a regional perspective, recovery rates appear to be higher in the southern region than in other regions. However, there were no significant differences in the recovery rate among the remaining regions or shelf positions.

Estimated median rates of recovery based upon reefs where coral cover was increasing ranged from approximately 10 to $25 \mathrm{yr}$. These estimates agree with other estimates from the GBR: 10 to 15 yr (Moran et al. 1985); 10 to 20 yr (Pearson 1974); 20 to 40 yr (Endean 1973); at least 50 yr (Done 1988); and elsewhere: Guam, 20 to 31 yr (Randall 1973); Guam, 11 yr (Colgan 1981); Hawaii, 3 yr (substantial recolonisation) (Branham 1973). Recovery periods should be compared with caution as estimates depend on the definition of recovery and may be optimistic if they concentrate on cover alone and ignore species diversity or colony size-structure.

We found evidence that some reefs may not recover. Approximately $25 \%$ of the reefs that were recovering from an Acanthaster planci outbreak had a negative growth rate. While projection of future trends based on past history is often tenuous, the prognosis for recovery on these reefs is poor. The variability in observed rates of change is not surprising as a number of biotic and abiotic factors affect recolonisation and growth (Buddemeier \& Kinzie 1976, Pearson 1981): reproductive success, larval survival, dispersal patterns, settlement patterns, competition, temperature, salinity, turbidity and storm action, to name a few. The definition of 'recovery' is arbitrary, so remnant populations of $A$. planci may also have contributed to a decline after a reef was declared to be recovering. Finally, there is the consideration of anthropogenic factors. Extreme reductions in hard coral cover may not be detrimental to the long-term survival of a reef if recruitment and growth can occur. If environmental conditions are such that recruitment is hampered and growth slowed, other benthic organisms may dominate (Hughes 1994).

Table 5. Estimated percentage (and number) of recovering reefs that displayed positive and negative growth rates

\begin{tabular}{|lcc|}
\cline { 2 - 3 } Region & $\begin{array}{c}\text { Percentage (no.) of } \\
\text { reefs displaying a } \\
\text { negative growth rate }\end{array}$ & $\begin{array}{c}\text { Percentage (no.) of } \\
\text { reefs displaying a } \\
\text { positive growth rate }\end{array}$ \\
\hline Far Northern & $12.5(3)$ & $87.5(21)$ \\
Northern & $29.6(8)$ & $70.4(19)$ \\
Central & $23.5(4)$ & $76.5(13)$ \\
Southern & $25.0(2)$ & $75.0(6)$ \\
\hline
\end{tabular}


The estimate of $25 \%$ of the reefs with negative growth rates that may not recover is high; on severely affected reefs that are remote from sources of propagules, coral cover may not increase for a number of years after the outbreak.

Repeated disturbance may contribute to low coral cover and poor recovery on some reefs (Hughes \& Connell 1999). Over the past 3 decades, Acanthaster planci outbreaks have occurred over much shorter intervals than the $>100$ yr required for some reefs to achieve a $30 \%$ increase in hard coral (Moran et al. 1992). Reefs dominated by fast-growing species of coral (e.g. Acropora spp.) may have sufficient time between outbreaks to recover. However, reefs dominated by slow-growing species are unlikely to have time to recover. Repeated disturbance would lead to a further decline in these species, which has the potential to cause community structure to shift toward fast-colonising and fast-growing species (Cameron et al. 1991).

\section{Summary}

We have used manta tow surveys to make the first regional and decadal scale observations on coral recovery after Acanthaster planci outbreaks on the GBR Unlike other parts of the world, the majority of reefs on the GBR are likely to recover after disturbance from $A$ planci. Most of the reefs studied showed positive growth rates; however, there was evidence to suggest that some other reefs may never recover. The variable nature of recovery illustrates the difficulties faced when trying to determine the long-term effects of impacts. Further work is required to identify environmental factors that may be useful for predicting rate of recovery. The distribution of coral cover (on reefs with no A. planci outbreak history) and starfish outbreaks varied with region. Further study is required to determine if this is an artifact of the survey method, or a result of anthropogenic factors.

Acknowledgements. This work formed part of the Long-term Monitoring Program at the Australian Institute of Marine Science. The Authors thank the past and present members of the Long-term Monitoring Team and the skippers and crews of the RV 'Sirius', RV 'The Harry Messel' and RV 'Lady Basten'. This manuscript benefited greatly from discussions held with H. Sweatman. D.A.J.R. was supported by the Cooperative Research Center for the Ecologically Sustainable Development of the GBR. This is AIMS contribution no. 1004

\section{LITERATURE CITED}

Bass DK, Miller IR (1995) Crown-of-thorns starfish and coral surveys using the manta tow and scuba search techniques. Long-term Monitoring of the Great Barrier Reef, Standard Operational Procedure No. 1. Australian Institute of Marine Science, Townsville

Bell PRF (1992) Eutrophication and coral reefs -- some examples in the Great Barrier Reef lagoon. Wat Res 26:553-568

Birkeland C, Lucas J (1990) Acanthaster planci: major management problem on coral reefs. CRC Press, Boca Raton

Branham JM (1973) The crown of thorns on coral reefs. Bioscience 23:219-226

Buddemeier RW, Kinzie RA (1976) Coral growth. Oceanogr Mar Biol Annu Rev 14:183-225

Cameron AM, Endean R, DeVantier LM (1991) Predation on massive corals: are devastating population outbreaks of Acanthaster planci novel events? Mar Ecol Prog Ser 75: 251-258

Colgan MW (1981) Succession and recovery of a coral reef after predation by Acanthaster planci (L.). Proc 4th Int Coral Reef Symp 2:333-338

Connell JH (1997) Disturbance and recovery of coral assemblages. Coral Reefs 16:\$101-\$113

Connell JH, Hughes TP, Wallace CC (1997) A 30-year study of coral abundance, recruitment, and disturbance at several scales in space and time. Ecol Monogr 67:461-488

De'ath G (1992) Sightability as an indicator of bias in manta tow surveys of Acanthaster planci: comment on Fernandes, Marsh, Moran and Sinclair. Coral Reefs 11:119-121

Done TJ (1985) Effects of two Acanthaster outbreaks on coral community structure: the meaning of devastation. Proc 5 th Int Coral Reef Congr 5:315-320

Done TJ (1987) Simulation of the effects of Acanthaster planci on the population structure of massive corals in the genus Porites: evidence of population resilience? Coral Reefs 6 : $75-90$

Done TJ (1988) Simulation of recovery of pre-disturbance size structure in populations of Porites spp. damaged by the crown of thorns starfish Acanthaster planci. Mar Biol 100: $51-61$

Done TJ, Kenchington RA, Zell LD (1981.) Rapid, large area, reef resource surveys using a manta board. Proc 4 th Int Coral Reef Symp 1:299-308

Done TJ, Osborne K, Navin KF (1988) Recovery of corals postAcanthaster progress and prospects. Proc 6th Int Coral Reef Symp 2:137-142

Endean R (1973) Population explosions of Acanthaster planci and associated destruction of hermatypic corals in the Indo-West Pacific region. In: Jones AO, Endean R (eds) Biology and geology of coral reefs, Vol 2. Academic Press, London, p 389-438 
Endean R, Stablum W (1973) The apparent extent of recovery of reefs of Australia's Great Barrier Reef devastated by the crown-of-thorns starfish. Atoll Res Bull 168:1-26

Endean R, Cameron AM, DeVantier LM (1988) Acanthaster planci predation on massive corals: the myth of rapid recovery of devastated reefs. Proc 6th Int Coral Reef Symp $2: 143-148$

Fernandes L (1990) Effect of the distribution and density of benthic target organisms on manta tow estimates of their abundance. Coral Reefs 9:116-165

Fernandes L, Marsh H, Moran PJ. Sinclair D (1990) Bias in manta tow surveys of Acanthaster planci. Coral Reefs 9 : $155-160$

Fernandes L, Marsh H, Sinclair DF (1992) Manta tow counts as indices of the distribution and abundance of Acanthaster planci: a reply to De'ath. Coral Reefs 11:179-181

Fisk DA, Harriott VJ, Pearson RG (1988) The history and status of crown-of-thorns starfish and corals at Green Island reef, Great Barrier Reef. Proc 6th Int Coral Reef Symp 2: $149-155$

Hatcher BG, Johannes RE, Robertson AI (1989) Review of research relevant to the conservation of shallow tropical marine ecosystems. Oceanogr Mar Biol Annu Rev 27:337-41.4

Hughes TP (1994) Catastrophes, phase shifts, and large-scale degradation of a Caribbean coral reef. Science 265: $1547-1551$

Hughes TP, Connell JH (1999) Multiple stressors on coral reefs: a long-term perspective. Limnol Oceanogr 44:932-940

Hughes TP, Ayre DJ, Connell JH (1992) The evolutionary ecology of corals. Trends Ecol Evol 9:292-298

McCullagh P, Nelder JA \{1989\} Generalized linear models, 2nd edn. Chapman and Hall, London

Miller IR, De'ath G (1996) Effects of training on observer performance in assessing benthic cover by means of the manta tow technique. Mar Freshw Res 47:19-26

Miller IR, Müller R (1997) A quality control procedure for

Editorial responsibility: Otto Kinne (Editor)

Oldendorf/Luhe, Germany observer agreement of manta tow benthic cover estimates. Proc 8th Int Coral Reef Symp 2:1475-1478

Moran PJ (1986) The Acanthaster phenomenon. Oceanogr Mar Biol Annu Rev 24:379-480

Moran PJ, De'ath G (1992a) Estimates of the abundance of the crown-of-thorns starfish Acanthaster planci in outbreaking and non-outbreaking populations on reefs within the Great Barrier Reef. Mar Biol 113:509-515

Moran PJ, De'ath G (1992b) Suitability of the manta tow technique for estimating relative and absolute abundances of crown-of-thorns starfish (Acanthaster planci L.) and corals. Aust J Mar Freshw Res 43:357-378

Moran PJ, Bradbury RH, Reichelt RE (1985) Mesoscale studies of the crown of thorns/coral interaction: a case history from the Great Barrier Reef. Proc 5th Int Coral Reef Congr 5:321-326

Moran PJ, De'ath G, Baker VJ, Bass DK, Christie CA, Miller IR, Miller Smith BA, Thompson AA (1992) Pattern of outbreaks of crown-of-thorns starfish (Acanthaster planci L.) along the Great Barrier Reef since 1986. Aust J Mar Freshw Res 43:555-568

Moss AJ, Rayment GE, Reilly N, Best EK (1992) A preliminary assessment of sediments and nutrient exports from Queensland coastal catchments. Environmental Technical Report No. 5. Queensland Department of Environment \& Heritage, Brisbane

Pearson RG (1974) Recolonization by hermatypic corals of reefs damaged by Acanthaster. Proc 2nd Int Coral Reef Symp 2:207-215

Pearson RG (1981) Recovery and recolonization of coral reefs. Mar Ecol Prog Ser 4:105-122

Randall RH (1973) Coral reef recovery following extensive damage by the 'crown of thorns' starfish Acanthaster planci (L.). Publ Seto Mar Biol Lab 20:469-489

Snedecor GW, Cochran WG (1980) Statistical methods, 7th edn. The lowa State University Press, Ames

Submitted: March 9, 1999; Accepted: October 28, 1999

Proofs received from author(s): March 20, 2000 